\title{
LA POLISEMIA DEL CONTROL DE CONVENCIONALIDAD INTERNO
}

\author{
POLYSEMY OF INTERNAL \\ CONVENTIONALITY CONTROL
}

\begin{abstract}
Miriam Lorena HenríQuez Viñas*
doi:10.11144/Javeriana.IL14-24.pcci
\end{abstract}

* Abogada, Universidad Nacional del Comahue (Argentina). Magíster en Derecho Público, Pontificia Universidad Católica de Chile. Doctora en Ciencias Jurídicas, Universidad de Santiago de Compostela (España). Profesora de Derecho Constitucional de la Universidad Alberto Hurtado, Santiago, Chile. Correos electrónicos: miriamhenriquez@yahoo.es -mhenriqu@uahurtado.cl 


\section{RESUMEN}

El presente artículo es el resultado de una investigación desarrollada a partir del análisis de la jurisprudencia de la Corte Interamericana de Derechos Humanos y de la doctrina especializada sobre el control de convencionalidad con un marcado acento crítico. La principal conclusión de este trabajo es que no existe un concepto definitivo de control de convencionalidad interno, sino que se trata más bien de un concepto híbrido, inacabado y actualmente controvertido, que se ha ido construyendo de manera paulatina por la Corte Interamericana de Derechos Humanos por medio de sus sentencias. Esta situación genera incertidumbre respecto del concepto mismo de control de convencionalidad, su naturaleza, destinatarios, parámetro y objeto de control, así como los efectos de la declaración de inconvencionalidad.

Palabras claves autora: Control de convencionalidad interno, sistema de protección de los derechos, tratados internacionales, jurisprudencia interamericana, derechos humanos.

Palabras clave descriptores: Derechos humanos, tratados, jurisprudencia. 


\section{ABSTRACT}

This article is the result of research developed from the analysis of the jurisprudence of the Inter-American Court of Human Rights and the doctrine specialized on conventionality control with a marked critical accent. The main conclusion of this work is that there is no definitive concept of internal conventionality control, but is rather a hybrid concept, currently unfinished and controversial, which has been built up gradually by the Inter-American Court of Human Rights through their judgments. This creates uncertainty about the very concept of conventionality, its nature, recipients, parameter and object of control, and the effects of the declaration of unconventionality.

Keywords author: Internal conventionality control, protection system of rights, international agreements, interamerican jurisprudence, human rights. Keywords plus: Human rights, treaties, jurisprudence.

\section{SUMARIO}

INTRODUCCIÓN.- I. EL CONTROL DE CONVENCIONALIDAD: UNA NOCIÓN ORIGINARIAMENTE HÍBRIDA.- II. EL CONTROL DE CONVENCIONALIDAD: UN CONCEPTO INACABADO.- A. ¿Quiénes son los sujetos destinatarios del control de convencionalidad? .- B. ¿Cuál es el parámetro y objeto del control de convencionalidad?.- 1. La jurisprudencia interamericana como parámetro de control interno de convencionalidad.-2. El derecho convencional como parámetro de control interno de convencionalidad.- 3. El objeto del control de convencionalidad.- III. El CONTROL DE CONVENCIONALIDAD: ¿UN CONTROL NORMATIVO O UN EJERCICIO DE INTERPRETACIÓN?.- IV. CONCLUSIÓN.- BibliografíA. 
INTRODUCCIÓN

La aparición explícita de la noción de control de convencionalidad en el sistema regional americano de derechos humanos, a partir de la primera década de este siglo, vía construcción pretoriana de la Corte Interamericana de Derechos Humanos, ha generado interés en la doctrina especializada del Derecho Internacional de los Derechos Humanos, del Derecho Constitucional y del Derecho Procesal Constitucional.

Sin embargo, pese a tratarse de un concepto vinculado también con la Teoría de las Fuentes del Derecho su análisis no se ha nutrido de insumos provenientes de aquella. Lo anterior propicia la persistencia de una serie de interrogantes que iré planteando a lo largo de este trabajo, con el objeto de evidenciarlas como cuestiones pendientes de definir y que originan la polisemia del control de convencionalidad.

La tesis que sostendré en este trabajo es que no existe un concepto definitivo de control de convencionalidad interno, sino que se trata más bien de un concepto híbrido, inacabado y actualmente controvertido.

De esta forma, el presente estudio se enfocará en el denominado control de convencionalidad interno, en oposición al control de convencionalidad internacional o externo que realiza la Corte Interamericana de Derechos Humanos (en adelante Corte Interamericana o Corte), resorte de todos los órganos del Estado, pero fundamentalmente de los jueces, y que implica una verificación de no contradicción entre las normas jurídicas internas susceptibles de aplicarse en un caso concreto, por un lado, y el corpus iuris convencional, por el otro.

Para la consecución del objetivo planteado seguiré el plan de análisis que se detalla a continuación. En primer término abordaré el control de convencionalidad y su naturaleza originaria híbrida entre el Derecho Constitucional y el Derecho Internacional de los Derechos Humanos. En segundo lugar, daré cuenta de que el concepto de control de convencionalidad no es definitivo, sino que se ha ido construyendo de manera paulatina 
en el devenir de la jurisprudencia de la Corte Interamericana. Para finalizar, buscaré dejar en evidencia que tal concepto es controvertido, debido a que parte de la doctrina concibe al control de convencionalidad como un control normativo, y otro sector lo considera como un ejercicio de interpretación, lo que deriva en efectos distintos según se lo afronte desde una u otra perspectiva.

Aclaro que no trataré las siguientes cuestiones relacionadas con el control de convencionalidad por exceder el objetivo planteado: a) La dinámica interactiva entre el Derecho Interno y el Derecho Internacional de los Derechos Humanos desde la perspectiva de las fuentes del Derecho; b) la teoría del bloque constitucional de los derechos humanos y su principio iluminador pro persona; c) el diálogo entre la Corte Interamericana y los tribunales nacionales; d) el fundamento del control de convencionalidad, que se deduce de los artículos 1.1, 2 y 29 de la Convención Americana sobre Derechos Humanos y de los principios pacta sunt servanda y bona fide; e) el objetivo del control de convencionalidad, situado para algunos en la creación de patrones hermenéuticos, y para otros en el desarrollo de un ius commune interamericano; f) la búsqueda del posible equilibrio entre la jurisdicción internacional y las jurisdicciones nacionales vía margen de apreciación nacional; y g) las consecuencias y efectos del ejercicio del control de convencionalidad y la asignación de responsabilidades a los Estados contraventores del orden interamericano.

I. EL CONTROL DE CONVENCIONALIDAD: UNA NOCIÓN ORIGINARIAMENTE HÍBRIDA

Como anticipé en la Introducción, el concepto de control de convencionalidad fue en su primera configuración esencialmente híbrido, por cuanto en este se combinaron elementos tanto del Derecho Internacional de los Derechos Humanos como del Derecho Constitucional. En particular me refiero al 
ensamble del control internacional, del control comunitario y del control de constitucionalidad ${ }^{1}$.

Lo afirmado se demuestra en las referencias que tanto los votos concurrentes del juez Sergio García Ramírez como la decisiones de la Corte Interamericana de Derechos Humanos, entre los años 2004 a 2007, realizaron en conjunto al control de constitucionalidad y al control de convencionalidad, y consideraron a ambos como controles normativos que deben realizar los jueces nacionales al momento de decidir el derecho aplicable.

En tal sentido, en el caso de Trabajadores Cesados del Congreso vs. Perú, de 2006, la Corte razonó que los órganos del Poder Judicial no solo deben realizar un control de constitucionalidad sino también uno de convencionalidad, pues se concibe a ambos controles normativos como una tarea de los jueces, a quienes corresponde verificar que la normativa aplicable sea conforme a la Convención Americana sobre Derechos Humanos (en adelante la Convención Americana o Convención), a la jurisprudencia interamericana y a la Constitución del Estado. Así, en el párrafo 128 expresó:

"Cuando un Estado ha ratificado un tratado internacional como la Convención Americana, sus jueces también están sometidos a ella, lo que les obliga a velar porque el efecto útil de la Convención no se vea mermado o anulado por la aplicación de leyes contrarias a sus disposiciones, objeto $y$ fin. En otras palabras, los órganos del Poder Judicial deben ejercer no solo un control de constitucionalidad, sino también 'de convencionalidad' ex officio entre las normas internas y la Convención Americana, evidentemente en el marco de sus respectivas competencias y de las regulaciones procesales correspondientes" 2 .

1 Cuando me refiero al control internacional aludo al control que se realiza por el órgano jurisdiccional competente en el ámbito internacional o supranacional, para determinar el cumplimiento de las obligaciones derivadas de un tratado internacional por un Estado determinado. El control comunitario, por su parte, permite verificar el cumplimiento del Derecho Comunitario por parte de los Estados partes de la Unión, por ejemplo la europea.

2 CIDH. Trabajadores Cesados del Congreso (Aguado Alfaro y otros) vs. Perú. Sentencia de excepciones preliminares, fondo, reparaciones y costas. Serie C $\mathrm{N}^{\circ} 158$, pár. 128 (24 de noviembre de 2006). 
Por su parte, en el año 2007, la Corte reiteró el criterio anterior en el caso Boyce y otros vs. Barbados, hizo referencia a su jurisprudencia precedente y explicitó en el párrafo 78: " $E l$ análisis del CJCP no debería haberse limitado a evaluar si la LDCP era inconstitucional. Más bien, la cuestión debería haber girado en torno a si la ley también era 'convencional. Es decir, los tribunales de Barbados, incluso el CJCP y ahora la Corte de Justicia del Caribe, deben también decidir si la ley de Barbados restringe o viola los derechos reconocidos en la Convención"”.

Cabe decir que, sin perjuicio de las primeras referencias a ambos tipos de control como controles normativos que comparten una lógica semejante, estos difieren al menos en cuatro aspectos: en cuanto al órgano encargado de formularlos, a la forma en que se realizan, al parámetro de control y a sus efectos.

En este sentido, el control interno de convencionalidad, es difuso, concreto, su parámetro de control son ciertos tratados de derechos humanos y la jurisprudencia interamericana, y sus efectos son la anticonvencionalidad o inconvencionalidad de la norma interna que contradice el plexo convencional internacional.

El segundo, el control de constitucionalidad es, según el modelo de justicia constitucional adoptado, un control difuso realizado por todos los jueces nacionales o concentrado en una Corte o Tribunal Constitucional, abstracto o concreto, cuyo parámetro de control es la Constitución, y sus efectos son la inaplicación o invalidación de la norma infraconstitucional que contradice o infringe la Carta Fundamental.

Como se observa, y pese a las diferencias apuntadas, algunas decisiones jurisprudenciales parecen haber solapado, en un primer momento de la definición del control de convencionalidad, el ámbito lógico y natural en que este y el control de constitucionalidad se desarrollan ${ }^{4}$. Empero, en sentencias sucesivas, la

3 CIDH. Boyce y otros vs. Barbados. Sentencia de excepciones preliminares, fondo, reparaciones y costas. Serie $\mathrm{C} \mathrm{N}^{\circ} 169$, pár. 78 (20 de noviembre de 2007).

4 Ver W. Carnota, La diferenciación entre control de constitucionalidad, control de convencionalidad y control de compatibilidad, XV Anuario Iberoamericano de Justicia Constitucional, 58 (2011). 
Corte Interamericana fue configurando el control de convencionalidad como uno diferente y autónomo respecto del control de constitucionalidad.

\section{EL CONTROL DE CONVENCIONALIDAD: \\ UN CONCEPTO INACABADO}

Desde 2003 el concepto de control de convencionalidad se ha ido construyendo de manera progresiva por la jurisprudencia de la Corte Interamericana, cuestión que puede constatarse al reconocer sus primeras alusiones en el voto concurrente razonado del juez García Ramírez en el caso Myrna Mack Chang vs. Perús, para luego ocupar un lugar central en las sentencias de la Corte, desde del fallo Almonacid Arellano y otros vs. Chile de $2006^{6}$.

La construcción paulatina de la institución se demuestra en una primera y cauta referencia a una "especie" de control de convencionalidad ${ }^{7}$ en la sentencia Almonacid Arellano y otros vs. Chile, cuyo considerando 124 expresó:

5 La primera referencia al control de convencionalidad fue durante el voto concurrente razonado en el caso Mirna Mack Chang, en que el juez García Ramirez afirmó: "Para los efectos de la Convención Americana y del ejercicio de la jurisdicción contenciosa de la Corte Interamericana, el Estado viene a cuentas en forma integral, como un todo. En este orden, la responsabilidad es global, atañe al Estado en su conjunto y no puede quedar sujeta a la división de atribuciones que señale el Derecho interno. No es posible seccionar internacionalmente al Estado, obligar ante la Corte solo a uno o algunos de sus órganos, entregar a éstos la representación del Estado en el juicio -sin que esa representación repercuta sobre el Estado en su conjunto- y sustraer a otros de este régimen convencional de responsabilidad, dejando sus actuaciones fuera del 'control de convencionalidad' que trae consigo la jurisdicción de la Corte internacional". CIDH. Myrna Mack Chang vs. Guatemala. Sentencia de excepciones preliminares, fondo, reparaciones y costas. Serie C No 101, pár. 27 ( 25 de noviembre de 2003). Luego, el mismo magistrado reiteró su postura en los casos Tibi vs. Ecuador. Serie C N ${ }^{\circ} 114$ (7 de septiembre de 2004); Raxcacó Reyes vs. Guatemala. Serie $\mathrm{C} \mathrm{N}^{\circ} 129$ (15 de septiembre de 2005); y López Alvarez vs. Honduras. Serie C Nº 138 (1 de febrero de 2006).

6 CIDH. Almonacid Arellano y otros vs. Chile. Sentencia de excepciones preliminares, fondo, reparaciones y costas. Serie C N 154, pár. 12 (26 de septiembre de 2006).

7 A juicio de Claudio Nash, tal mención a una "especie" de control de convencionalidad pretendió dar cuenta de una posición prudente y clarificadora de la naturaleza diversa que tiene esta figura de aquel ejercicio propio del derecho constitucional. C. Nash, Control de convencionalidad. Precisiones conceptuales y desafíos a la luz de la jurisprudencia de la Corte Interamericana de Derechos Humanos, en El diálogo transjudicial de los tribunales constitucionales entre sí y con las Cortes Internacionales de Derechos Humanos, 359-385 (H. Nogueira, Coord., Librotecnia, Santiago, 2012). 
"La Corte es consciente que los jueces y tribunales internos están sujetos al imperio de la ley y, por ello, están obligados a aplicar las disposiciones vigentes en el ordenamiento jurídico. Pero cuando un Estado ha ratificado un tratado internacional como la Convención Americana, sus jueces, como parte del aparato del Estado, también están sometidos a ella, lo que les obliga a velar porque los efectos de las disposiciones de la Convención no se vean mermadas por la aplicación de leyes contrarias a su objeto y fin, y que desde un inicio carecen de efectos jurídicos. En otras palabras, el Poder Judicial debe ejercer una especie de 'control de convencionalidad' entre las normas jurídicas internas que aplican en los casos concretos y la Convención Americana sobre Derechos Humanos. En esta tarea, el Poder Judicial debe tener en cuenta no solamente el tratado, sino también la interpretación que del mismo ha hecho la Corte Interamericana, intérprete última de la Convención Americana".

Luego, en las sentencias posteriores a 2006, se realizaron alusiones directas al control de convencionalidad, de forma que se han configurado progresivamente sus elementos y características centrales. Asimismo, la gradualidad de la noción se advierte en la extensión de los órganos encargados de realizarla, del procedimiento y del objeto del control de convencionalidad, temáticas que se analizarán a continuación.

\section{A. ¿Quiénes son los sujetos destinatarios del control de convencionalidad?}

En una primera fase, la Corte impuso el deber de ejercer el control de convencionalidad interno a los jueces domésticos. En la sentencia del caso Almonacid Arellano y otros vs. Chile se expresó que tal obligación corresponde a "sus jueces, como parte del aparato del Estado" y en definitiva "al Poder Judicial". Tal criterio se reiteró en el caso Trabajadores Cesados del Congreso vs. Perú que afirmó el deber "de los órganos del Poder Judicial" de ejercer no solo un control de constitucionalidad sino también de convencionalidad ${ }^{9}$. En el mismo sentido, en el caso Boyce y

8 CIDH. Almonacid Arellano y otros vs. Chile. Sentencia de excepciones preliminares, fondo, reparaciones y costas. Serie C No 154, pár. 124 (26 de septiembre de 2006).

9 CIDH. Trabajadores Cesados del Congreso (Aguado Alfaro y otros) vs. Perú. Sentencia de excepciones preliminares, fondo, reparaciones y costas. Serie C No 158, pár. 128 (24 
otros vs. Barbados, la Corte precisó que el control de convencionalidad correspondía realizarlo a "los tribunales de Barbados, incluso el Comité Judicial del Consejo Privado y ahora la Corte de Justicia del Caribe"10.

Fue en 2010, en el caso Cabrera García y Montiel Flores vs. México, que la Corte incluyó entre los sujetos encargados de ejercer el control de convencionalidad no solo a los jueces sino también "a los órganos vinculados a la administración de justicia en todos los niveles"11, con particular referencia a los tribunales constitucionales que en ciertos ordenamientos son órganos independientes del Poder Judicial. En este caso, a partir del párrafo 226 de la sentencia, la Corte mencionó a los "tribunales de la más alta jerarquía en la región" que han ejercido el control de convencionalidad y destacó a la Sala Constitucional de la Corte Suprema de Justicia de Costa Rica, al Tribunal Constitucional de Bolivia, a la Suprema Corte de Justicia de República Dominicana, al Tribunal Constitucional del Perú, a la Corte Suprema de Justicia de la Nación de Argentina y a la Corte Constitucional de Colombia.

Alguna doctrina ha señalado que, luego del caso Cabrera García y Montiel Flores vs. México, el alcance del control se extendió a todos los jueces nacionales cualquiera sea su jerarquía, grado, cuantía, materia de especialización o competencia (local o federal). En tal sentido, Nogueira Alcalá afirma que el control de convencionalidad debe ser ejercido por todo órgano que ejerza jurisdicción dentro del Estado, lo que comprendería a los tribunales constitucionales, a los órganos que ejercen jurisdicción electoral, todo juez especial que determina el ordenamiento jurídico nacional, además de los jueces ordinarios de todas las instancias ${ }^{12}$.

de noviembre de 2006).

10 CIDH. Boyce y otros vs. Barbados. Sentencia de excepciones preliminares, fondo, reparaciones y costas. Serie $\mathrm{C} \mathrm{N}^{\circ} 169$, pár. 78 (20 de noviembre de 2007).

11 CIDH. Cabrera García y Montiel Flores vs. México. Sentencia de excepción preliminar, fondo, reparaciones y costas. Serie C N²20, pár. 225 (26 de noviembre de 2010).

12 H. Nogueira, Los desafíos del control de convencionalidad del corpus iuris interamericano para los tribunales nacionales, en especial, para los Tribunales Constitucionales, en El diálogo transjudicial de los tribunales constitucionales entre sí y con las Cortes Internacionales de 
Finalmente en 2011, en el caso Gelman vs. Uruguay, la Corte completó la ampliación del sujeto destinatario del control expandiéndolo a toda autoridad pública. Así lo señaló la sentencia en el párrafo 239:

"La legitimación democrática de determinados hechos o actos en una sociedad está limitada por las normas y obligaciones internacionales de protección de los derechos humanos reconocidos en tratados como la Convención Americana, de modo que la existencia de un verdadero régimen democrático está determinada por sus características tanto formales como sustanciales, por lo que, particularmente en casos de graves violaciones a las normas del Derecho Internacional de los Derechos, la protección de los derechos humanos constituye un límite infranqueable a la regla de mayorías, es decir, a la esfera de lo 'susceptible de ser decidido' por parte de las mayorías en instancias democráticas, en las cuales también debe primar un "control de convencionalidad (...), que es función y tarea de cualquier autoridad pública y no solo del Poder Judicial"13.

La "evolución" relatada da cuenta de cómo la Corte Interamericana extendió de manera gradual la obligación de realizar el control interno de convencionalidad desde los jueces del Poder Judicial a toda autoridad pública, y lo convirtió en un verdadero control difuso de convencionalidad.

Por otro lado, la mencionada ampliación gradual construida por la Corte plantea, por lo menos, la siguiente interrogante: ¿Para el control de convencionalidad interno tiene relevancia la existencia de controles concentrados de constitucionalidad de las normas infraconstitucionales?

Autores como Néstor Sagüés afirman que el asunto del destinatario del control no ofrece problemas en un ordenamiento

Derechos Humanos, 279-351 (H. Nogueira, Coord., Librotecnia, Santiago, 2012).

13 CIDH. Gelman vs Uruguay. Sentencia de fondo y reparaciones. Serie C N ${ }^{\circ} 221$, pár. 239 (24 de febrero de 2011). Por su parte, Juana Ibáñez destaca este fallo no solo por referir que todas las autoridades están obligadas a ejercer el control de convencionalidad, sino al contexto en que éste debe ser aplicado y que es "en instancias democráticas", cuestión que se reitera en los casos Chocrón Chocrón vs. Venezuela. Serie C No. 227 (1 de julio de 2011); López Mendoza vs. Venezuela. Serie C No. 233 (1 de septiembre de 2011); Fontevecchia y D' Amico vs. Argentina. Serie C No. 238 (29 de noviembre de 2011), entre otros. J. Ibáñez, Control de convencionalidad: precisiones para su aplicación desde la jurisprudencia de la Corte Interamericana de Derechos Humanos, VIII Anuario de Derechos Humanos, 109 (2012). 
que posee un sistema de control difuso o mixto de constitucionalidad, pero se complejiza en aquellos sistemas de control concentrado de constitucionalidad ${ }^{14}$. Esto, por cuanto Sagüés supone que solo el órgano que ejerce el control de constitucionalidad puede ejercer el control de convencionalidad, cuestión coherente con la concepción que este tiene de este último, es decir, un control de la validez de la norma interna respecto de la normativa interamericana.

En ese orden de ideas, el autor resuelve la problemática planteada en los sistemas de control concentrado de constitucionalidad, con base en la doctrina sentada por la propia Corte. Esta permite que el control de convencionalidad lo realicen los órganos destinatarios en el marco de sus respectivas competencias y de las regulaciones procesales pertinentes, por tanto, el juez del Poder Judicial deberá remitir los autos al tribunal habilitado para ejercer el control de constitucionalidad, con el fin de que este ejecute la simultánea revisión de convencionalidad ${ }^{15}$.

En un sentido diferente, Eduardo Ferrer Mac-Gregor opina que el control de convencionalidad procede cualquiera sea el modelo de justicia de constitucional, difuso o concentrado ${ }^{16}$. Lo que a su juicio los diferenciaría es una cuestión de grado en cuanto a los efectos que se producen de su ejercicio. Así, en los llamados sistemas difusos de control de constitucionalidad, el grado de

14 N. Sagüés, Obligaciones internacionales y control de convencionalidad, 8 Revista Estudios Constitucionales, 1, 121 (2010).

15 Óp. cit., p. 122.

16 En un sentido coincidente Allan Brewer sostiene: "En nuestro criterio, sin embargo, cuando afirmamos que todos los jueces nacionales tienen competencia para ejercer el control de convencionalidad, es para ejercerlo, de manera que aún en los países que tienen un sistema concentrado de control de constitucionalidad, y a pesar del control concentrado de constitucionalidad existente, todos los jueces y tribunales deben aplicar la Convención Americana y por ello están llamados a ejercer el control difuso de convencionalidad, lo que implica que en caso de incompatibilidad o conflicto entre una norma interna que deban aplicar para resolver un caso concreto y normas de la Convención Americana, deben dar preferencia a estas y desaplicar las normas de derecho interno contrarias a la Convención". A. Brewer, El control de convencionalidad con particular referencia a la garantía del derecho a la protección judicial mediante un recurso sencillo y rápido y efectivo de amparo de los derechos humanos, en http://www.allanbrewercarias.com/Content/449725d9-f1cb-474b-8ab2-41efb849fea2/ Content/I,\%201,\%201055\%20\%20EL \%20CONTROL $\% 20$ DE $\% 20$ CONVENCIONALIDAD $\% 20$ por $\% 201 \mathrm{a} \% 20$ Corte $\% 20$ IDH $\% 20$ Y $\% 20$ LA $\% 20$ INSTITUCI $\%$ C $3 \% 93$ N $\% 20$ DEL \%20AMPARO,\%2018\%20sept.\%202012.doc).pdf (27-28 de septiembre de 2012). 
control de convencionalidad resulta de mayor alcance al tener todos los jueces nacionales la atribución de no aplicar la norma inconvencional. En cambio, afirma, el grado de intensidad del control difuso de convencionalidad disminuirá en aquellos sistemas de control concentrado de constitucionalidad, que permite a los jueces realizar solo una "interpretación convencional", es decir una "interpretación conforme" de la Constitución, de la Convención y de la jurisprudencia convencional, pero que no les autoriza - por carecer de tal competencia-a dejar de aplicar la norma ${ }^{17}$.

En mi opinión, la extensión progresiva impulsada por la Corte por medio de sus fallos desde los jueces -como aplicadores del Derecho y eventualmente con facultades para no aplicar una norma en ejercicio del control difuso de constitucionalidad-a toda autoridad pública plantea la ampliación de las facultades de todos los órganos del Estado, los cuales, a partir de este control, tendrán atribuciones jurisdiccionales con competencias invalidatorias o de inaplicación. El efecto descrito contraviene el principio de legalidad que rige en todo Estado de Derecho, en el cual las competencias de los órganos del Estado -y fundamentalmente de aquellos que ejercen jurisdicción- solo pueden ser fijadas por la Constitución o la ley.

Además, es contrario a lo resuelto por la propia Corte, que en el caso Trabajadores Cesados del Congreso vs. Perú matizó el control de convencionalidad al consagrar la posibilidad de realizarlo por el Poder Judicial "ex officio", es decir sin necesidad de la solicitud de las partes, pero "evidentemente en el marco de sus respectivas competencias y de las regulaciones procesales correspondientes" ${ }^{\prime \prime}$.

17 E. Ferrer Mac-Gregor, Interpretación conforme y control difuso de convencionalidad. El nuevo paradigma para el juez mexicano, 9 Revista Estudios Constitucionales, 2, 581 (2011).

18 CIDH. Trabajadores Cesados del Congreso (Aguado Alfaro y otros) vs. Perú. Sentencia de excepciones preliminares, fondo, reparaciones y costas. Serie C No 158, pár. 12 (24 de noviembre de 2006). 


\section{B. ¿Cuál es el parámetro y objeto del control de convencionalidad?}

El parámetro y el objeto del control de convencionalidad también se han ido delineando de modo progresivo en la jurisprudencia emanada de la Corte Interamericana, lo que ha generado dudas e incertidumbres sobre el alcance del control interno de convencionalidad.

En una primera etapa, iniciada en 2006 a partir del fallo Almonacid Arellano y otros vs. Chile, el parámetro de control señalado por la Corte fue la Convención Americana sobre Derechos Humanos y la interpretación que de esta efectuó la Corte, es decir, su jurisprudencia.

Las problemáticas que plantea el parámetro de control de convencionalidad se analizarán a continuación, y será posible distinguir los desafíos que significa precisar el ámbito de la jurisprudencia y del Derecho convencional interamericanos.

1. La jurisprudencia interamericana como parámetro de control interno de convencionalidad

La Corte se ha referido a la jurisprudencia interamericana como parámetro de control de convencionalidad de manera sostenida de la siguiente forma: "En esta tarea, el Poder Judicial debe tener en cuenta no solamente el tratado, sino también la interpretación que del mismo ha hecho la Corte Interamericana, intérprete última de la Convención Americana"19. De esta manera, el tribunal interamericano dispuso que cuando los tribunales y demás órganos nacionales ejerzan el control interno de convencionalidad consideren las normas de la Convención Americana, y además se guíen por la interpretación que de estas normas ha ido formulando la Corte Interamericana.

19 CIDH. Almonacid Arellano y otros vs. Chile. Sentencia de excepciones preliminares, fondo, reparaciones y costas, X. Serie C $\mathrm{N}^{\circ} 154$, pár. 12 (26 de septiembre de 2006). 
Que el material normativo controlante sea la exégesis que de la Convención ha hecho la Corte Interamericana, plantea una serie de cuestiones. Entre ellas, Francisco Zúñiga destaca la indefinición de lo que se entiende por jurisprudencia interamericana y si esta comprende tanto las interpretaciones vertidas en sentencias de casos contenciosos como las opiniones consultivas ${ }^{20}$.

Para comenzar, corresponde afirmar que no existe uniformidad de criterios respecto a la formación de la llamada jurisprudencia interamericana. Parte de la doctrina ha entendido que las opiniones consultivas solo son vinculantes para los Estados que las solicitaron, y por ende aquellas no formarían parte de esa jurisprudencia. En un sentido contrario, otros autores como Miguel Carbonell piensan que las opiniones consultivas de la Corte constituyen la jurisprudencia interamericana, y que son obligatorios los criterios interpretativos contenidos en los pronunciamientos de la Corte, sea que consten en sus sentencias, opiniones consultivas o en el dictado de medidas provisionales. En palabras de Carbonell: "Con la mayor amplitud posible, debemos reconocer plena eficacia a todos los pronunciamientos de la Corte IDH, con independencia del acto procesal del que emanen o del tipo de competencia que haya sido ejercida por la Corte"21.

En lo que respecta a las sentencias dictadas por la Corte en el ejercicio de la función contenciosa, nadie parece dudar de su valor jurídico vinculante para los Estados que aceptaron tal competencia e intervinieron en el proceso respectivo, es decir, que tienen efectos vinculantes inter partes. La complicación radica en que al parecer la Corte extendió la eficacia vinculante o fuerza orientadora de sus sentencias con efectos erga omnes a todos los Estados que reconocieron su competencia jurisdiccional.

Esta situación plantea para algunos una interpretación mutativa por adición, pues la Corte ha agregado algo al contenido

20 F. Zúñiga, Control de convencionalidad y tribunales nacionales. Una aproximación crítica, en El diálogo transjudicial de los tribunales constitucionales entre sí y con las Cortes Internacionales de Derechos Humanos, 387 - 447 (H. Nogueira, Coord., Librotecnia, Santiago, 2012).

21 M. Carbonell, Introducción general al control de convencionalidad, 83 (Editorial Porrúa, México D. F., 2013). 
inicial del Pacto aunque el texto literal de este no ha variado ${ }^{22}$. De esta forma, la interpretación formulada por la Corte tendrá el mismo valor que la letra del Pacto, sin un texto expreso que lo haya sostenido en el ordenamiento internacional y sin que algunos ordenamientos internos le dispensen a la jurisprudencia valor de precedente vinculante.

Otros autores, como Sergio García, matizan esta conclusión y aclaran que la interpretación únicamente tiene que ver con las normas. Lo que precisa García Ramírez cuando señala que "solo alcanza la interpretación de normas", es que la interpretación atiende únicamente a la fijación del sentido de las disposiciones convencionales, el entendimiento general del precepto para todos los fines aplicativos que este pueda tener, no así a los extremos específicos del caso en que se hizo la interpretación, que solo conciernen al Estado y a la víctima que comparecieron en el juicio ${ }^{23}$.

Además del debate e incertidumbre sobre el contenido de la jurisprudencia interamericana y las complejidades que plantea el supuesto alcance erga omnes de las sentencias contenciosas, el tema proyecta además otra serie de asuntos entre los que destacan: a) ¿Puede decidir un órgano jurisdiccional internacional, por medio de sus sentencias, que su propia jurisprudencia sea vinculante para los Estados cuando estos no lo han resuelto así?; b) ¿La jurisprudencia interamericana tiene valor de precedente vinculante o es una guía o pauta interpretativa para el ejercicio del control interno de convencionalidad?; c) ¿Pueden los tribunales internos, en el ejercicio del control de convencionalidad, formular interpretaciones propias sobre las normas del derecho internacional convencional interamericano?; d) ¿Cómo se resolvería una posible colisión entre el control interno de convencionalidad y el control internacional de convencionalidad a propósito de la interpretación de la Convención?

22 N. Sagüés, Obligaciones internacionales y control de convencionalidad, 8 Revista Estudios Constitucionales, 1, 126 (2010).

23 S. García, El control judicial interno de convencionalidad, 5 Revista del Instituto de Ciencias Jurídicas de Puebla, 28, 139 (2011). 
A mi juicio, en relación con la primera pregunta, la atribución del carácter de fuente formal del Derecho a la jurisprudencia que emana de los tribunales nacionales o internacionales solo puede ser decidida por la Constitución de cada Estado, y no por vía jurisprudencial de un tribunal internacional.

\section{El Derecho convencional como parámetro} de control interno de convencionalidad

En sentencias posteriores al caso Almonacid Arellano y otros vs. Chile, la Corte Interamericana amplió el parámetro de control de convencionalidad desde la Convención Americana a los demás tratados que son de su competencia material. Así fue afirmado en 2010 en la sentencia del caso Ibsen Cárdenas e Ibsen Peña vs. Bolivia, cuyo párrafo 199 dice: "El Tribunal recuerda que el objeto de su mandato es la aplicación de la Convención Americana y de otros tratados que le otorguen competencia" 24 . De este modo extiende el parámetro desde la Convención al Protocolo de San Salvador, Protocolo Relativo a la Abolición de la Pena de Muerte, Convención para Prevenir y Sancionar la Tortura, Convención de Belém do Pará para la Erradicación de la Violencia contra la Mujer, Convención sobre Desaparición Forzada de Personas, y a los demás tratados que sobre la materia puedan quedar comprendidos dentro de las atribuciones de la Corte Interamericana ${ }^{25}$.

Autores como Nogueira desarrollan aun más la competencia de la Corte y afirman que forman parte del parámetro de control aquellos tratados que no son de su competencia material, tales como la Convención sobre Derechos del Niño, el Convenio 169

24 CidH. Ibsen Cárdenas e Ibsen Peña vs Bolivia. Serie C Nº 217 (1 de septiembre de 2010).

25 Esta extensión fue tempranamente señalada en el voto razonado emitido por el magistrado García Ramírez, en la sentencia del caso Trabajadores Cesados del Congreso vs. Perú, según la cual, si bien el tribunal ha tenido a la vista la aplicabilidad y la aplicación de la Convención, tal función se despliega "a otros instrumentos de igual naturaleza, integrantes del corpus juris convencional de los derechos humanos de los que es parte el Estado". Voto razonado concurrente, caso Trabajadores Cesados del Congreso (Aguado Alfaro y otros) vs. Perú. Sentencia de excepciones preliminares, fondo, reparaciones y costas, pár. 2. Serie C No 158 (24 de noviembre de 2006). 
de la OIT y otros instrumentos internacionales que aseguran y garantizan derechos humanos.

En un sentido más restringido, con el que coincido, autores como Sergio García Ramírez sostienen que en el examen de asuntos litigiosos, la Corte no adopta decisiones que impliquen la aplicación directa de aquellos convenios sobre los cuales carece de competencia material, a la manera en lo que hace con respecto a los instrumentos que le atribuyen esa facultad. Por el contrario, recoge conceptos de aquellos para fines de interpretación, como el establecimiento del contexto, conocimiento de estándares, inserción en el marco del derecho internacional contemporáneo, etc. ${ }^{26}$. Esta aclaración de García Ramírez implica que la Corte considera los tratados sobre los que no ostenta competencia material solo para la interpretación y aplicación de normas de la Convención y, por tanto, en ejercicio de las potestades de las que se haya investida. Sin embargo, eso no significa que ellos sean parte del parámetro de control y que deban aplicarse de manera directa por las autoridades, si el Estado no los ha ratificado en ejercicio del control de convencionalidad.

Considero que la indefinición recién presentada plantea, por un lado, un problema significativo para quienes deben ejercer el control interno de convencionalidad, ya que tal indeterminación ejerce presión en los polos certeza jurídica-justicia formal. Por otro lado, todo indica que los tratados que no son parte del derecho convencional interamericano solo pueden ser parámetro de control internacional o externo, es decir, aquel que realiza la Corte Interamericana; en este mismo sentido, no pueden ser del control de convencionalidad interno, pues de lo contrario afecta la ya señalada certeza jurídica-justicia formal y también la soberanía estatal, al pretender vincular al Estado por tratados que no ha decidido libremente suscribir ni incorporar al Derecho interno.

26 S. García, Óp. cit. 


\section{El objeto del control de convencionalidad}

En una primera etapa el control interno de convencionalidad alcanzaba a las leyes contrarias al objeto y fin de la Convención para luego ampliarse a las "normas contrarias a su objeto y fin", e incluso también a las "normas o prácticas internas contrarias al objeto y fin del instrumento internacional o del estándar internacional de protección de los derechos humanos".

Así, por ejemplo, se refirió a las "leyes internas" la sentencia del caso Almonacid Arellano y otros vs. Chile, en el ya mencionado párrafo 124. Más adelante, en 2008, la Corte señaló en la sentencia sobre el caso Heliodoro Portugal vs. Panamá que el control de convencionalidad comprende también a las prácticas internas. En tal sentido, el párrafo 180 del fallo señaló:

"Precisamente, respecto a la adopción de dichas medidas, es importante destacar que la defensa u observancia de los derechos humanos a la luz de los compromisos internacionales en cuanto a la labor de los operadores de justicia, debe realizarse a través de lo que se denomina "control de convencionalidad", según el cual cada juzgador debe velar por el efecto útil de los instrumentos internacionales, de manera que no quede mermado o anulado por la aplicación de normas o prácticas internas contrarias al objeto y fin del instrumento internacional o del estándar internacional de protección de los derechos humanos"27.

En consecuencia, es posible apreciar que la Corte Interamericana ha aumentado progresivamente, $\mathrm{y}$ sin mayor justificación, el alcance del objeto del control interno de convencionalidad desde la ley a las normas internas, lo que incluye decretos o reglamentos e incluso a las Constituciones estatales, para llegar a abarcar las propias prácticas internas, tales como las resoluciones judiciales $\mathrm{y}$ las decisiones administrativas.

Como es observable, esa constante extensión del objeto del control genera incertidumbres sobre su alcance y permite especular que todo acto de naturaleza estatal podría comprenderse

27 CIDH. Heliodoro Portugal vs. Panamá. Sentencia de excepciones preliminares, fondo, reparaciones y costas. Serie C N 186, pár. 180 (12 de agosto de 2008). 
dentro de las prácticas internas. De hecho, cierta doctrina ya ha entendido que cuando se habla de prácticas internas implica tanto las judiciales como todo tipo de prácticas estatales conducentes a la observancia efectiva de los derechos consagrados en la Convención ${ }^{28}$.

\section{El CONTROL DE CONVENCIONALIDAD: ¿UN CONTROL} NORMATIVO O UN EJERCICIO DE INTERPRETACIÓN?

Parte de la doctrina sostiene que el control de convencionalidad es un control normativo, mientras otro sector opina que se trata de un ejercicio de interpretación entre normas que consagran derechos fundamentales. Las consecuencias de estas distintas perspectivas incidirá - entre otros asuntos-en los efectos que se le asigna al control de convencionalidad: inaplicación-invalidez o interpretación conforme a la Convención.

Algunos autores, como Francisco Zúñiga, Gonzalo Aguilar, Néstor Sagüés, Allan Brewer y Juan Carlos Hitters, conciben al control de convencionalidad interno como un control normativo entre las disposiciones jurídicas internas y la normativa interamericana, y lo asimilan, incluso en su estructura, al control de constitucionalidad. Tal control normativo, que realizan los jueces nacionales de oficio o a petición de parte -y que involucraría también a las demás autoridades públicasconsistiría en la obligación de verificar si existe conformidad o contradicción entre las normas jurídicas internas que se aplican en los casos concretos, por un lado, y la Convención y los patrones interpretativos que el tribunal interamericano ha acuñado a su respecto, por otro, en aras de la tutela de los derechos humanos ${ }^{29}$.

28 G. Aguilar, El control de convencionalidad y el rol del juez nacional como juez de derechos humanos, en El diálogo transjudicial de los tribunales constitucionales entre sí y con las Cortes Internacionales de Derechos Humanos, 449- 508 (H. Nogueira, Coord., Librotecnia, Santiago, 2012).

29 Entre quienes sostienen que el control de convencionalidad interno es un control normativo destaca por su rotundidad Francisco Zúñiga, con base en un análisis crítico según el cual al conflicto entre tratados internacionales y normativa interna los tribunales de justicia deben darle el tratamiento de conflicto de fuentes; así se confiere a los tratados 
Por otro lado, ciertos autores como Ernesto Rey, Claudio Nash, Eduardo Ferrer Mac-Gregor, Humberto Nogueira, Víctor Bazán, Karlos Castilla, entre otros, consideran que el control de convencionalidad implica un ejercicio interpretativo que, en caso de lagunas o antinomias, las autoridades deben hacer en el ámbito de sus competencias para preferir la normativa de origen internacional que permite una mejor protección de los derechos humanos ${ }^{30}$.

del rubro una aplicación preferente cuando corresponda, y así no se podría justificar una inaplicación de la ley fundada en un supuesto de control de convencionalidad. F. Zúñiga, Óp. cit., pp. 387-447. Por su parte, Gonzalo Aguilar, define el control de convencionalidad interno como un control normativo que consiste en la facultad de los magistrados de contrastar la norma dictada por el poder legislativo -y, eventualmente, por el poder constituyente- con la norma contenida en los tratados internacionales que han sido ratificados por el Estado, para hacer prevalecer estas últimas sobre las normas emanadas del poder legislativo y, a fortiori, sobre las normas emanadas del poder ejecutivo. Corresponde decir que Aguilar niega el control de convencionalidad en el ámbito internacional como un control normativo, y solo le reconoce este carácter al control interno. Así, en caso de que el juez nacional constate la incompatibilidad entre ambas normas tendrá que preferir aquella que otorgue una protección mayor al individuo o que menos restrinja sus derechos fundamentales. G. Aguilar, Óp. cit., pp. 449-508. Néstor Pedro Sagüés afirma que el control de convencionalidad es un acto de revisión o fiscalización de la sumisión de las normas nacionales a la Convención Americana de Derechos Humanos y a la exégesis que a este instrumento da la Corte Interamericana de Derechos Humanos. Asimismo agrega: "Se trata, como se ha apuntado, de un análisis de confrontación normativa". N. Sagüés, Óp. cit., p. 120.

Allan Brewer se refiere al control de convencionalidad interno como aquel que ejercen los jueces o tribunales nacionales al juzgar la validez de los actos del Estado, al confrontarlos no solo con la Constitución respectiva, sino con el elenco de derechos humanos y de obligaciones de los Estados contenidos en la Convención Americana, o al aplicar las decisiones vinculantes de la Corte Interamericana, decidiendo en consecuencia, conforme a sus competencias, la anulación de las normas nacionales o su desaplicación en el caso concreto. Óp.cit. p. 2. Ver también J. Hitters, Control de constitucionalidad y control de convencionalidad. Comparación (criterios fijados por la Corte Interamericana de Derechos Humanos), 7 Revista Estudios Constitucionales, 2, 122 (2009).

30 De forma categórica, Ernesto Rey Cantor distingue entre el problema jurídico de la aplicación de la norma, por un lado; y lo referente a su interpretación, por el otro. Para ser precisos señala que, seleccionada la disposición legal para el caso, corresponde al juez acudir a un sistema de interpretación de la norma internacional que reconoce a los derechos humanos. ¿Cuál es esa interpretación? Para Rey Cantor es "el objeto y fin del tratado", que según la jurisprudencia de la Corte Interamericana es la interpretación pro homine. Así, según Rey Cantor este es el control de convencionalidad en sede interna. E. Rey, Controles de convencionalidad de las leyes y derechos humanos. Homenaje a Héctor Fix Zamudio, 262 (Editorial Porrúa, México, 2008). En la misma postura, Claudio Nash es enfático en cuanto a que el control de convencionalidad es un ejercicio hermenéutico que consiste en la verificación que realiza la Corte Interamericana y todos los agentes estatales, de la adecuación de las normas jurídicas internas a la Convención y a los estándares interpretativos desarrollados en la jurisprudencia de dicho tribunal, aplicando en cada caso concreto aquella interpretación que se ajuste a las obligaciones internacionales del Estado y dé efectividad a los derechos consagrados convencionalmente. C. Nash, Óp. cit., pp. 359-385. Por su parte, Ferrer Mac-Gregor explica que el control de convencio- 
La diferencia entre una concepción y otra es relevante por los efectos que se deducen de su ejercicio. En el primer supuesto será la invalidez-inaplicabilidad, y en el segundo la responsabilidad internacional. Además, porque en el caso del control normativo se recurrirá al criterio jerárquico para resolver un conflicto entre la norma interna y la norma interamericana, cuestión que no ocurrirá en el evento que se considere al control de convencionalidad como ejercicio de interpretación.

Para la primera postura, es posible constatar la aplicación del criterio jerárquico en el ya tantas veces citado caso Almonacid Arellano y otros vs. Chile, en que la Corte afirmó que la norma inconvencional "desde un inicio (...) carece de efectos jurídicos". Así la norma interna sería inválida por contradecir a la Convención o a la jurisprudencia interamericana, siendo la invalidez el efecto propio de la aplicación del criterio jerár-

nalidad es un proceso interpretativo de armonización entre la normativa internacional y la interna, que "implica, incluso, en algunas ocasiones, dejar de aplicar la primera, al resultar de mayor alcance protector la norma nacional, conforme al principio pro persona y también derivado de la obligación general de respetar los derechos y libertades previstos en los tratados internacionales". E. Ferrer Mac-Gregor, Óp.cit., p 550. A su vez, Víctor Bazán, conceptualiza al control de convencionalidad como aquel en que se efectúa una interpretación de las prácticas internas a la luz o al amparo del corpus iuris capital en materia de derechos humanos acerca del cual aquel ejerce competencia material. V. Bazán, El control de convencionalidad: incógnitas, desafíos y perspectivas, en Justicia constitucional y derechos fundamentales. El control de convencionalidad 2011, 17 -55 (Bazán y Nash, Eds., Unión Gráfica Ltda., Bogotá D. C., 2012).

Por su parte, Nogueira sostiene: "La función de los órganos judiciales en este plano es hacer sus mejores esfuerzos para otorgar efecto útil a las normas internacionales, más aun cuando ellas constituyen derechos que emanan de la dignidad humana, los cuales deben ser efectivizados por el Estado juez a través de la adopción de las resoluciones jurisdiccionales conforme a las obligaciones generales establecidas por los artículos 1.1 y 2 de la CADH, como asimismo una interpretación favor persona y posibilitar el goce más amplio de los derechos de acuerdo al artículo 29 de la misma Convención, evitando así incurrir en responsabilidad internacional por violación de derechos humanos a través de eventuales conductas omisivas". H. Nogueira, Los desafios del control de convencionalidad del corpus iuris interamericano, 135 Boletín Mexicano de Derecho Comparado, 1185-1186 (2012). Karlos Castilla distingue entre control de convencionalidad y "especie de control de convencionalidad". El primero sólo le correspondería realizarlo la Corte Interamericana y es esencialmente un control normativo. La "especie de control de convencionalidad" consistiría en la obligación de observar y aplicar el contenido de la Convención Americana por medio de una interpretación de derechos y libertades acorde al tratado. A su juicio el control de convencionalidad no permite a los jueces declarar como inconvencional una ley o acto, pues no están autorizados para ello, de este modo pueden hacer siempre y por la obligación que tienen, solo la interpretación antes señalada. K. Castilla, El control de convencionalidad. Un nuevo debate en México a partir de la sentencia del caso Radilla Pachecho, XI Anuario Mexicano de Derecho Internacional, 603 (2011). 
quico. Respecto de esta aseveración corresponde preguntarse si la invalidación produce sus efectos pro futuro o retroactivos, generales o particulares, asuntos que la Corte Interamericana todavía no ha definido.

Otra secuela de la consideración del control de convencionalidad como un control normativo implicaría que la Convención -e incluso los demás tratados de derechos humanos según la ampliación formulada por la Corte- tendría jerarquía supraconstitucional para todos los Estados firmantes. Claramente, el hecho de que sean las sentencias de un tribunal internacional las que definan la jerarquía de los tratados, supone una revolución para la Teoría de las Fuentes del Derecho y para la propia noción de supremacía constitucional, cuestión no compartida por parte importante de la doctrina ${ }^{31}$, entre quienes me incluyo, y celebrada por otro sector relevante de esta ${ }^{32}$.

Lo afirmado vuelve a plantear una serie de incógnitas: a) ¿Cuál es la fuente del Derecho que debe reconocer jerarquía a los tratados de derechos humanos?; b) ¿Puede decidir un órgano jurisdiccional internacional, como la Corte Interamericana, que el derecho convencional tiene jerarquía supraconstitucional mediante su jurisprudencia?; c) ¿Cómo se compatibilizan los

31 Francisco Zúñiga considera que el control de convencionalidad supone: "Lógica y sistemáticamente, en cuanto control de regularidad, en razón de la infracciones que se imputen al Estado, al derecho material interamericano, admitir en la práctica, o que la Convención Americana sobre Derechos Humanos o el corpus iuris convencional, interamericano, son supraconstitucionales". Agrega que esta conclusión carece de sustento constitucional al menos en Chile. F. Zúñiga, Óp. cit. En el mismo sentido ver: M. Henríquez, Análisis de la jurisprudencia recaída en recursos de protección y el control de convencionalidad (19892011), en El diálogo transjudicial de los tribunales constitucionales entre sí y con las Cortes Internacionales de Derechos Humanos, 249-259 (H. Nogueira, Coord., Librotecnia, Santiago, 2012).

32 Ernesto Jinesta afirma: "El control de convencionalidad ejercido por los tribunales y salas constitucionales debe ser extendido a los preceptos constitucionales que contrarían el parámetro de convencionalidad por su carácter, eventualmente, supraconstitucional. La doctrina debe asumir, naturalmente, la mutación positiva de los principios de supremacía constitucional y de la fidelidad constitucional, así como el replanteamiento de la teoría clásica de las fuentes del Derecho, como fenómenos generados por la eclosión del control de convencionalidad". E. Jinesta, Control de convencionalidad ejercido por los Tribunales y Salas Constitucionales, en El control difuso de convencionalidad. Diálogo entre la Corte Interamericana de Derechos Humanos y los jueces nacionales, 2-28 (E. Ferrer Mac-Gregor, Coord., Fundación Universitaria de Derecho, Administración y Política, México D. F., 2012). 
efectos del ejercicio del control de convencionalidad en relación con el régimen de invalidación que estructura el ordenamiento de cada Estado americano?

Considero que en un sistema de Derecho Positivo respetuoso de la certeza jurídica y de las propias finalidades del Estado de Derecho, sobre todo, de la limitación del poder, la jerarquía de los tratados de derechos humanos y el régimen de invalidación de sus normas, solo puede ser decidida por la Constitución de cada Estado. Insisto que en ello radica la noción misma de supremacía constitucional.

Para la tesis contraria, la regla básica es la interpretación conforme al principio pro homine o favor persona, según el cual, entre enunciados normativos con atributos y garantías de derechos fundamentales, siempre debe aplicarse aquel que asegure mayor cantidad de atributos o garantías de los derechos, y no dar lugar a la aplicación del criterio de jerárquico. En este último sentido, el denominado control de convencionalidad constituiría en estricto rigor un metacriterio interpretativo, en cuya virtud los jueces internos obtendrían insumos para promover la derrotabilidad recíproca de normas que no son de diferente jerarquía, sino que, de conformidad a los criterios pro homine o favor persona, serían susceptibles de ser aplicadas de manera alternativa, sin invalidar ni declarar inaplicable a ninguna, cuando ofrezcan estándares disímiles de protección de los derechos humanos.

De esta forma, los jueces y demás autoridades públicas, en cumplimiento de la normativa internacional que el Estado ha recibido internamente, están obligados a realizar un ejercicio interpretativo que busque la efectividad de los derechos consagrados convencionalmente, más cuando estos constituyen derechos que emanan de la dignidad humana. Estos derechos deben ser efectivizados por el Estado mediante la adopción de resoluciones judiciales conforme a las obligaciones establecidas por los artículos 1.1 y 2 de la Convención, y mediante la interpretación favor persona de acuerdo con el Artículo 29 de esa Convención, con el fin de evitar que el Estado incurra 
en responsabilidad internacional. Para realizar este ejercicio interpretativo, el destinatario del control también debe tener en consideración la jurisprudencia interamericana. 


\section{CONCLUSIÓN}

El control de convencionalidad interno es una institución originada pretorianamente por la Corte Interamericana de Derechos Humanos, cuyos perfiles no han sido definidos con precisión desde un inicio, sino que se han construido de manera paulatina en el devenir jurisprudencial. Lo dicho hace del control de convencionalidad un modelo todavía inacabado, en que además la doctrina desarrolla tesis diversas sobre su naturaleza, lo que da lugar a numerosas incertidumbres relativas al alcance de los destinatarios, parámetro, objeto y efectos del control, que este texto buscó evidenciar.

Para dar respuesta a algunas de las interrogantes planteadas en este trabajo, considero que el control de convencionalidad es distinto al control de constitucionalidad, pues si bien ambos son de carácter normativo, difieren al menos en cuanto a los órganos encargados del control, a la forma como se realizan, a los parámetros utilizados y sus efectos.

Por otro lado, considero que el control de convencionalidad debe circunscribirse, por tratarse de un control normativo, solo a aquellos órganos con facultades para declarar la invalidez o aplicación de las normas; alcanzar como material controlante únicamente a aquellos tratados respecto de los cuales la Corte tiene competencia material; y tener por objeto a la normativa interna del Estado.

Para finalizar, enfatizo que en un sistema de Derecho Positivo respetuoso de la certeza jurídica y de las propias finalidades del estado de Derecho, principalmente de la limitación del poder, la jerarquía de los tratados de derechos humanos, el valor de fuente formal del Derecho de la jurisprudencia nacional o internacional y el régimen de invalidación de las normas solo puede ser decidida por la Constitución de cada Estado. 


\section{BIBLIOGRAFÍA}

\section{Libros}

Carbonell, M., Introducción general al control de convencionalidad, 83 (Editorial Porrúa, México D.F., 2013).

Rey, E., Controles de convencionalidad de las leyes y derechos humanos. Homenaje a Héctor Fix Zamudio, 262 (Editorial Porrúa, México D.F., 2008).

\section{Contribuciones en obras colectivas}

Aguilar, G., El control de convencionalidad y el rol del juez nacional como juez de derechos humanos, en El diálogo transjudicial de los tribunales constitucionales entre sí y con las Cortes Internacionales de Derechos Humanos, 449-508 (H. Nogueira, Coord., Librotecnia, Santiago, 2012).

Bazán, V., El control de convencionalidad: incógnitas, desafíos y perspectivas, en Justicia constitucional y derechos fundamentales. El control de convencionalidad 2011, 17-55 (Bazán y Nash, Eds., Unión Gráfica Ltda., Bogotá D. C., 2012).

Carnota, W., La diferenciación entre control de constitucionalidad, control de convencionalidad y control de compatibilidad, en XV Anuario Iberoamericano de Justicia Constitucional, 5-66 (2011).

Castilla, K., El control de convencionalidad. Un nuevo debate en México a partir de la sentencia del caso Radilla Pachecho, en XI Anuario Mexicano de Derecho Internacional, 593-624 (2011).

Henríquez, M., Análisis de la jurisprudencia recaída en recursos de protección y el control de convencionalidad (1989-2011), en El diálogo transjudicial de los tribunales constitucionales entre sí y con las Cortes Internacionales de Derechos Humanos, 249-259 (H. Nogueira, Coord., Librotecnia, Santiago, 2012).

Ibáñez, J., Control de convencionalidad: precisiones para su aplicación desde la jurisprudencia de la Corte Interamericana de Derechos Humanos, en VIII Anuario de Derechos Humanos, 103-113 (2012).

Jinesta, E., Control de convencionalidad ejercido por los tribunales y salas constitucionales, en El control difuso de convencionalidad. Diálogo entre la Corte Interamericana de Derechos Humanos y los jueces nacionales, 2-28 (E. Ferrer Mac-Gregor, Coord., Fundación Universitaria de Derecho, Administración y Política, México D. F., 2012).

Nash, C., Control de convencionalidad. Precisiones conceptuales y desafíos a la luz de la jurisprudencia de la Corte Interamericana de Derechos Humanos, en El diálogo transjudicial de los tribunales constitucionales entre sí y con las Cortes Internacionales de Derechos Humanos, 359-385 (H. Nogueira, Coord., Librotecnia, Santiago, 2012).

Nogueira, H., Los desafíos del control de convencionalidad del corpus iuris interamericano para los tribunales nacionales, en especial, para los Tribunales 
Constitucionales, en El diálogo transjudicial de los tribunales constitucionales entre sí y con las Cortes Internacionales de Derechos Humanos, 279-351 ( H. Nogueira, Coord., Librotecnia, Santiago, 2012).

Zúñiga, F., Control de convencionalidad y tribunales nacionales. Una aproximación crítica, en El diálogo transjudicial de los tribunales constitucionales entre sí y con las Cortes Internacionales de Derechos Humanos, 387-447 (H. Nogueira, Coord., Librotecnia, Santiago, 2012).

\section{Artículos}

Ferrer Mac-Gregor, E., Interpretación conforme y control difuso de convencionalidad. El nuevo paradigma para el juez mexicano, 9 Revista Estudios Constitucionales, 2, 531-622 (2011).

García, S., El control judicial interno de convencionalidad, 5 Revista del Instituto de Ciencias Jurídicas de Puebla, 28, 123-159 (2011).

Hitters, J., Control de constitucionalidad y control de convencionalidad. Comparación (criterios fijados por la Corte Interamericana de Derechos Humanos), 7 Revista Estudios Constitucionales, 2, 109-128 (2009).

Nogueira, H., Los desafíos del control de convencionalidad del corpus iuris interamericano, 135 Boletín Mexicano de Derecho Comparado, 1167-1220, (2012).

Sagüés, N., Obligaciones internacionales y control de convencionalidad, 8 Revista Estudios Constitucionales, 1, 117-135 (2010).

\section{Fuentes digitales}

Brewer, A., El control de convencionalidad con particular referencia a la garantía del derecho a la protección judicial mediante un recurso sencillo y rápido y efectivo de amparo de los derechos humanos, en http://www.allanbrewercarias.com/ Content/449725d9-f1cb-474b-8ab2-41efb849fea2/Content/I,\%201,\%201055\%20 $\% 20$ EL $\% 20$ CONTROL $\% 20$ DE $\% 20$ CONVENCIONALIDAD $\% 20$ por $\% 20$ $1 \mathrm{a} \% 20$ Corte $\% 20$ IDH $\% 20$ Y $\% 20$ LA $\% 20$ INSTITUCI $\%$ C3 $\% 93$ N $\% 20$ DEL $\% 20$ AMPARO,\%2018\%20sept.\%202012.doc).pdf (27-28 de septiembre de 2012).

\section{Casos}

CIDH. Myrna Mack Chang vs. Guatemala. Serie C No 101 (25 de noviembre de 2003). CIDH. Tibi vs. Ecuador. Serie C No 114 (7 de septiembre de 2004).

CIDH. Raxcacó Reyes vs. Guatemala. Serie C Nº 129 (15 de septiembre de 2005). CIDH. Almonacid Arellano y otros vs. Chile. Serie C N 154 (26 de septiembre de 2006).

CIDH. López Álvarez vs. Honduras. Serie C Nº 138 (1 de febrero de 2006). 
CIDH. Trabajadores Cesados del Congreso (Aguado Alfaro y otros) vs. Perú. Serie C N N $^{\circ} 158$ (24 de noviembre de 2006).

CIDH. Boyce y otros vs. Barbados. Serie C Nº 169 (20 de noviembre de 2007).

CIDH. Heliodoro Portugal vs. Panamá. Serie C Nº 186 (12 de agosto de 2008).

CIDH. Cabrera García y Montiel Flores vs. México. Serie C N²20 (26 de noviembre de 2010).

CidH. Ibsen Peña vs Bolivia. Serie C N²17 (1 de septiembre de 2010).

CIDH. Gelman vs. Uruguay. Serie C No 221 (24 de febrero de 2011).

CIDH. Chocrón Chocrón vs. Venezuela. Serie C N²27 (1 de julio de 2011).

CIDH. López Mendoza vs. Venezuela. Serie C N² 233 (1 de septiembre de 2011).

CIDH. Fontevecchia y D’ Amico vs. Argentina. Serie C N² 238 (29 de noviembre de 2011). 
